\title{
The expression of core fucosylated E-cadherin in cancer cells and lung cancer patients: prognostic implications
}

\author{
Fei GENG ${ }^{1}$, Bi Zhi SHI ${ }^{1}$, Yun Feng YUAN ${ }^{2}$, Xing Zhong WU ${ }^{1 *}$ \\ ${ }^{1}$ Department of Biochemistry and Molecular Biology, Fudan University Medical Center, Shanghai 200032, China \\ ${ }^{2}$ Department of Thoracic Surgery, Zhongshan Hospital, Fudan University, Shanghai 200032, China
}

\begin{abstract}
It is well documented that the glycosylation of E-cadherin is correlated with cancer metastasis, but whether Ecadherin could be core fucosylated remains largely unknown. We found that E-cadherin was core fucosylated in highly metastatic lung cancer cells while absent in lowly metastatic lung cancer cells. Since $\alpha-1,6$ Fucosyltransferase $(\alpha-1,6$ FucT) is known to catalyze the reaction of core fucosylation, we investigated the biological function of core fucosylation on E-cadherin by $\alpha-1,6$ FucT targeted RNAi and transfecting $\alpha-1,6$ FucT expression vector. As a result, calcium dependent cell-cell adhesion mediated by E-cadherin was strengthened with the reduction of core fucosylation on Ecadherin after RNAi and was weakened with the elevated core fucosylation on E-cadherin after $\alpha-1,6$ FucT over expression. Our data indicated that $\alpha-1,6$ FucT could regulate E-cadherin mediated cell adhesion and thus play an important role in cancer development and progression. Computer modeling showed that core fucosylation on E-cadherin could significantly impair three-dimensional conformation of N-glycan on E-cadherin and produce conformational asymmetry so as to suppress the function of E-cadherin. Furthermore, the relationship between the expression of core fucosylated E-cadherin and clinicopathological background of lung cancer patients was explored in lung cancer tissue of patients. It turns out to demonstrate that core fucosylated E-cadherin could serve as a promising prognostic indicator for lung cancer patients.
\end{abstract}

Keywords: Core fucosylated E-cadherin, prognosis, cancer metastasis, RNA interference, molecular modeling.

\section{INTRODUCTION}

$\alpha-1,6$ Fucosyltransferase ( $\alpha-1,6$ FucT) catalyzes the reaction of core fucosylation by transferring a fucosyl residue from GDP-fucose to the asparagine-linked GlcNAC residue of complex $\mathrm{N}$-glycans via $\alpha-1,6$ linkage. This process is regarded as an important manner of posttranslational modification and functional regulation of glycoproteins. In normal tissues, the content of core fucosylated N-linked oligosaccharide is rather low. However, with the tumorigenesis of some tissues such as liver, lung and stomach, its content increases dramatically [1].

Being a calcium-dependent transmembrane glycoprotein, E-cadherin has five-repeated extracellular domains and mediates cell-cell adhesion in a homotypic manner through

*Correspondence: Xing Zhong WU

Tel: 0086-21-54237697, Fax:0086-21-64278329;

E-mail: xz_wu@shmu.edu.cn the clustering of symmetric cis dimers of amino-terminal extracellular domains, which plays an essential role in regulating major cellular behaviors including cell growth, migration and aggregation [2-5]. Containing a histidine-alanine-valine (HAV) sequence which is essential for cell-cell adhesion, the N-terminal extracellular domain CAD1 plays a vital role in cell-cell contact [3,5]. Reduced levels of Ecadherin correlate with increased invasiveness in many human cancer cell types $[2,3]$. The presence of bisected high mannose type N-linked glycan was ascertained on Ecadherin $[6,7]$, but whether E-cadherin could be the substrate of $\alpha-1,6$ FucT kept unclear before.

RNA interference (RNAi) is known as a response to double-stranded RNA (dsRNA), which results in sequencespecific mRNA degradation and gene silencing. As a conservative response during the course of the evolution of plants and animals, RNAi directs PTGS (post-transcriptional gene silencing) and mediates resistance to both endogenous parasitic and exogenous pathogenic nucleic acids [8]. The ability to create stable "knock-down" cell lines 
expands the utility of RNAi in mammalian cells by enabling examination of phenotypes and lays the groundwork for phenotype-based genetic research [9]. The use of hairpin siRNA expression vectors for RNAi has provided a rapid and versatile method for assessing gene function in mammalian cells [10].

In order to ensure the presence of core fucosylated Ecadherin, we investigated its expression in highly metastatic cancer cells. In addition, we revealed that core fucosylation on E-cadherin could impair E-cadherin mediated cell adhesion by conformational remodeling of oligosaccharides and asymmetry of cis dimers. Moreover, different levels of E-cadherin expression in lung cancer patients were observed concomitantly with increased cancer metastasis and recurrence, providing clinical evidence for it to serve as a prognostic marker.

\section{MATERIALS AND METHODS}

\section{Cell lines and tissue samples}

Human lowly and highly metastatic lung giant cancer cells (95C, 95D) were purchased from the General Hospital of PLA (Beijing, China). The metastatic potential of $95 \mathrm{C}$ and $95 \mathrm{D}$ cells had been confirmed by Transwell invasion assay. Human ovarian cystadenocarcinoma cell line SKOV-3 was purchased from American Type Culture Collection (ATCC). Human cervical carcinoma HeLa, breast carcinoma MCF-7, lung adenocarcinoma A549, lung large cell carcinoma H460, gastric carcinoma SGC7901, histiocytoma U937 and Hepatoma SMMC-7721 cells were purchased from Institute of Biochemistry and Cell Biology, Chinese Academy of Sciences. MHCC97-H (highly metastatic hepatoma) and MHCC97-L (lowly metastatic hepatoma) were obtained from Liver Cancer Institute, Zhongshan Hospital, Fudan University. The cell lines were cultured in DMEM or RPMI1640 medium (Gibcol BRL) supplemented with $10 \%$ fetal calf serum. All cell lines grew at $37^{\circ} \mathrm{C}$ under $5 \% \mathrm{CO}_{2}$. The subjects enrolled in this study were 18 patients with lung cancer who underwent surgical resection between June and July in 2002 at Zhongshan Hospital, Fudan University (Shanghai, China). In addition, inflammatory pseudotumor and margin specimen of tumor tissue were used as control. Tumor samples were obtained during surgical resection and were snap-frozen in liquid nitrogen and stored at $-70^{\circ} \mathrm{C}$ until being used. Tumors were graded as well differentiated, moderately differentiated, or poorly differentiated. The patients were divided into five groups according to the prognosis: A (survival without tumor recurrence or metastasis); B1 (survival only with tumor recurrence), B2 (survival only with metastasis), B3 (survival with tumor recurrence and metastasis); $\mathrm{C}$ (death). The present project was approved by the hospital and written informed consent was obtained from patients who were included.

\section{Preparation of H1 RNA promoter}

By using $2 \mu \mathrm{l}$ of genome DNA extracted from 95C and 95D cells as template, H1 RNA promoter was amplified by PCR with High Fidelity PCR systems (Takara) and then purified with PCR Purification Kit (Watson Biotech, Inc). Upstream primer: 5'-CCATGGAATTCGAACGCTGACGTC-3', downstream primer: 5'-GCAAGCTTAGATCTGTGGTCTCATACAGAACTTATAAGATTCCC-3'.

\section{Construction of hairpin siRNA expression vector}

The vector of PB-H1 was constructed by inserting the fragment of $\mathrm{H} 1$ promoter in PBluescript SK II (+) plasmid. Then $\alpha-1,6$ FucT catalytic domain targeted hairpin sequence ( 5 ' -gatccctccgacaccgataccgacattcaagagatgtcggtatcggtgtcggatttttggaaa-3') was inserted immediately to $\mathrm{H} 1$ promoter in PB-H1 to construct $\alpha-1,6$ FucT targeted hairpin siRNA expression vector. The hairpin sequence was composed of two identical 19 nt sequence motifs in an inverted orientation, separated by a 9 bp spacer of nonhomologous sequence. The individual motif is $19 \mathrm{nt}$ long and corresponds to the coding region of catalytic domain of $\alpha-1,6$ FucT. The transcriptional termination signal of 5 Ts was added at the $3^{\prime}$ end of the inverted repeat.

\section{Transfection of RNAi expression vector and FUT8 expres- sion vector}

When growing to approximately $80 \%$ confluency in culture flasks, lung cancer cells were trypsinized, washed and resuspended in phosphate-buffered saline (PBS) at the density of $2.5 \times 10^{7}$ cell $/ \mathrm{ml}$. The cells were transferred to an electroporation cuvette (Eppendorf) with $5 \times 10^{6}$ cells $/ 0.2 \mathrm{ml}$ and transfected with $20 \mu \mathrm{g}$ hairpin siRNA vector, FUT8 expression vector and empty vector, respectively. A single pulse at $400 \mathrm{~V} / 45 \mu$ s was used for transfection. Then the electroporation cuvette was put on ice for $10 \mathrm{~min}$ and the cells were transferred to culture flasks. The cells were cultured in RPMI 1640 for $72 \mathrm{~h}$ and then selected by G418. Resistant cell clones were picked out and determined by lectin blotting.

\section{Immunocytochemical ABC method}

For the assay of $\mathrm{ABC}$ (Avidin-biotin enzyme-labelled complex), we plated Mocked cells as well as RNAi cells on glass slips in 6-well plates (Falcon). Glass slips were collected after $48 \mathrm{~h}$. After being washed for 2 times, cells were fixed with $4 \%$ paraformaldehyde in PBS for $20 \mathrm{~min}$. Washed with PBS for 3 times, cells was blocked with 1\% BSA (bovine serum albumin, Roche) in PBS for $1 \mathrm{~h}$. Cells were incubated with Bio-LCA (1:2000, Vector) for $1 \mathrm{~h}$ at room temperature, washed with PBS, and then incubated with Avidin$\operatorname{HRP}(1: 500$, Vector) for $1 \mathrm{~h}$ at room temperature. After being washed with PBS, cells were stained with $0.05 \%$ DAB and documented by photography.

\section{Indirect immunofluorescence staining}

The steps before blocking were the same as those in the immunocytochemical ABC method described above. Then cells were incubated with FITC-labeled LCA (1:2000) for $1 \mathrm{~h}$ at room temperature. After being washed with PBS, stained cells were mounted in Vectashield (Vector) and examined under an Olympus epifluorescence microscope. Photographs were taken with plus-zX-Pan film (Kodak).

\section{Flow cytometry analysis}

Subconfluent cells were detached with $0.2 \%$ trypsin $/ 0.04 \%$ EDTA, and the single-cell suspensions were resuspended in medium and incubated with an optimal concentration of Bio-LCA (1:2000) in wash buffer ( $1 \%$ BSA in PBS) for $1 \mathrm{~h}$ on ice. The cells were then washed 3 times and incubated with the appropriate Avidin-FITCconjugated antibody for $30 \mathrm{~min}$ on ice. After washing again for 3 times, the cells were resuspended in $500 \mu$ PBS. Cells were analyzed in a FAC scan flow cytometer (Becton-Dickinson Immunocytometry 
Systems, CA). Cells stained with secondary antibody served as controls.

\section{Lectin blotting}

After being washed with cold PBS for 3 times, cells were scraped from dishes and lysed in lysis buffer [20 mM Tris-HCl PH 7.5,10 mM EGTA, 2 mM EDTA, $1 \mathrm{mM}$ dithiothreitol (DTT), $1 \mathrm{mM}$ phenylmethylsulfonylfluoride (PMSF)]. The samples were fractionated by SDS-PAGE, transferred to immobilon NC membranes and immunoblotted with LCA. The immunoreactive proteins were visualized by enhanced chemiluminescence system (Perfect Biotech, Shanghai)

\section{Cell Proliferation assay}

All proliferation assays were carried out in quadruplicate wells in parallel 96-well microtiter plates. Cells were plated at a concentration of $1 \times 10^{4}$ cells per well in four parallel plates. Cells were incubated at $37^{\circ} \mathrm{C}$ with $5 \% \mathrm{CO}_{2}$. On $2 \mathrm{~d}, 4 \mathrm{~d}, 6 \mathrm{~d}$ and $8 \mathrm{~d}$, one plate was subjected to cell proliferation assay. In the MTT assay, cells were placed in culture medium (RPMI 1640 with $10 \%$ fetal calf serum) with $1 \mathrm{mg} / \mathrm{ml}$ of MTT (3-[4,5- dimethylthiazol-2-yl]-2,5diphenyltetrazolium bromide, Sigma) and incubated at $37^{\circ} \mathrm{C}, 5 \%$ $\mathrm{CO}_{2}$ for $4 \mathrm{~h}$. The medium was removed and the formazan crystals formed from MTT by NADH-generating dehydrogenases in metabolically active cells were dissolved in $200 \mu \mathrm{l}$ DMSO. The absorbance at $490 \mathrm{~nm}$ was determined on an $\mathrm{EL}_{\mathrm{X}} 800$ Microplate Reader (Bio-Tek Instruments, Inc).

\section{Cell adhesion to HUVEC}

HUVECs $\left(4 \times 10^{4} /\right.$ well $)$ were cultured to confluence in $150 \mu \mathrm{l}$ of culture medium in a 96-well cluster plate (Corning). HUVEC monolayer was then stimulated for $2 \mathrm{~h}$ with $10 \mathrm{ng} / \mathrm{ml} \mathrm{TNF} \alpha$. Mock/95D and RNAi/95D cells were plated at $1 \times 10^{5}$ cells/well on HUVEC monolayer. After $30 \mathrm{~min}, 1 \mathrm{~h}, 2 \mathrm{~h}, 4 \mathrm{~h}$ of adhesion, unattached cells were vigorously washed off with PBS. The attached cells were fixed with $4 \%$ paraformaldehyde for $10 \mathrm{~min}$, and observed under a phase contrast microscope (Olympus). Adherent 95D cells were counted under microscope in five random fields in each well. The percentage of adherent cells in total was calculated to show the affinity of cell adhesion to HUVEC. Each point stands for Mean \pm SD from at least five wells, and three separate experiments were carried out.

\section{Random cell migration assay by agarose drop explants [11]}

Before the assay cells were cultured in medium containing thymidine $(1 \mathrm{mM})$ for $24 \mathrm{~h}$ to keep both of test team and control team synchronized to eliminate the error for proliferation. $2 \%$ agarose was incubated at $45-55^{\circ} \mathrm{C}$ to melt and keep it melted in water bath at $37^{\circ} \mathrm{C}$. After growing to approximately $80 \%$ confluency in culture flasks, lung cancer cells were trypsinized, washed and resuspended at a density of $1 \times 10^{6}$ cells $/ \mathrm{ml}$ to obtain single cell suspension. After centrifugation, the cells were resuspend them in $50 \mu 110 \% \mathrm{FBS} /$ RPMI1640 medium. Then $20 \mu 12 \%(\mathrm{w} / \mathrm{v})$ agarose was added to form $0.6 \%$ agarose-cell suspension. A drop of $2 \mu 1$ suspension was added on a six-well plate and kept in room temperature for an $1 \mathrm{~h}$ to allow it to solidify. Its radius (R) was calculated in four directions and then cultured in RPMI 1640 medium. After $24 \mathrm{~h}$ and $48 \mathrm{~h}$, its radius (R') was calculated again to get their average value. (R'- R) reflects migration potential of cells. 10 drop explants were used for each team and three independent experiments were carried out.

\section{Cell aggregation assay}

To determine $\mathrm{Ca}^{2+}$-dependent cell-cell-adhesion, aggregation assays were performed as described previously [6, 12]. Cells were washed with PBS and treated with $0.01 \%$ trypsin in HEPESbuffered saline ( $37 \mathrm{mM} \mathrm{NaCl}, 5.4 \mathrm{mM} \mathrm{KCl}, 0.34 \mathrm{mM} \mathrm{NaH}_{2} \mathrm{PO}_{4}$, $5.6 \mathrm{mM}$ glucose, and $10 \mathrm{mM}$ HEPES) containing $2 \mathrm{mM} \mathrm{CaCl}_{2}$. Trypsinized cells were centrifuged, washed twice with HEPES with $2 \mathrm{mM} \mathrm{CaCl}_{2}$ and resuspended in the same buffer. The cells were singled using a pipette until no aggregates were monitored. To examine the calcium dependency, EDTA and EGTA with the final concentration of $5 \mathrm{mM}$ were added. To specify E-cadherin-dependency, $5 \mu \mathrm{g}$ of neutralizing antibody against E-cadherin was added to the experiments. Cells were allowed to aggregate for $30 \mathrm{~min}$ at $37^{\circ} \mathrm{C}$ with a constant rotation of $70 \mathrm{rpm}$. The extent of cell aggregation was calculated by measuring aggregation diameter in each field over a total of five randomly chosen fields using inverted microscope fitted with a ruler in eyepiece. Three independent assays were performed in quadruplicate.

\section{Gelatin zymography}

Gelatinase activity was assayed by zymography as described previously [13]. Mocked/95D cells and RNAi/95D cells grown at confluence were washed several times in PBS and then incubated with serum free medium for $48 \mathrm{~h}$ in the presence of DMSO or $1 \mu \mathrm{M}$ herbimycin A. The conditioned culture medium (CCM) was concentrated and equal amounts of proteins were subjected to electrophoresis in an $8 \%$ polyacrylammide gel containing $0.1 \%$ gelatin. After electrophoresis, the gel was washed with $50 \mathrm{mM}$ Tris- $\mathrm{HCl}$, $\mathrm{pH} 7.5$ containing $2.5 \%$ Triton-X 100 and then incubated in reaction buffer (50 mM Tris-HCl, pH 7.5 with $0.15 \mathrm{M} \mathrm{NaCl}, 10 \mathrm{mM} \mathrm{CaCl}_{2}$ ) overnight at $37^{\circ} \mathrm{C}$. The gel was stained with coomassie and then the gelatinase activity was visualized as clear bands on a stained background.

\section{Computer molecular modeling}

Molecular modeling was performed on a Silicon Graphics Indigo 2 workstation using Insight II software (MSI Inc). X-Ray crystal structures of E-cadherin and High Mannose Type N-linked Glycan were obtained by exhaustive searching of The Protein Data Bank (PDB) at the University of California, San Diego (http://www.rcsb. org/pdb/) [14].

\section{Immunoprecipitation (IP) and Western blotting}

Cells were grown to confluence on $100 \mathrm{~mm}$ dishes, rinsed twice in ice-cold complete PBS, and then harvested into IP lysis buffer containing $0.5 \%$ Triton $\mathrm{X}-100,120 \mathrm{mM} \mathrm{NaCl}, 15 \mathrm{mM}$ Tris- $\mathrm{HCl}$, $\mathrm{pH} 7.5,1 \mathrm{mM}$ phenylmethylsulfonylfluoride (PMSF), $0.1 \mathrm{mM}$ dithiothreitol (DTT), $10 \mu \mathrm{M}$ aprotinin, $10 \mu \mathrm{M}$ leupeptin. Human lung cancer tissues were grinded in liquid nitrogen and were homogenized in IP lysis buffer on ice. The extracts from cells and tissues were incubated in lysis buffer on ice for $30 \mathrm{~min}$ and centrifuged at $4^{\circ} \mathrm{C}, 14,000 \mathrm{~g}$ for $30 \mathrm{~min}$. The supernatants were mixed by rotation with LCA-agarose beads (Vector) at $4^{\circ} \mathrm{C}$ overnight. LCA-agarose beads were washed for 3 times with wash buffer $(50 \mathrm{mM}$ Tris- $\mathrm{HCl}$, pH 7.5, $150 \mathrm{mM} \mathrm{NaCl}, 1 \mathrm{mM} \mathrm{MgCl} 2,0.5 \%$ NP-40, $1 \mathrm{mM}$ PMSF, $0.1 \mathrm{mM}$ DTT, $10 \mu \mathrm{M}$ aprotinin, $10 \mu \mathrm{M}$ leupeptin) and heated at 
$100^{\circ} \mathrm{C}$ in SDS sample buffer for $5 \mathrm{~min}$. The samples were fractionated by SDS-PAGE, transferred to Immobilon NC membranes, and immunoblotted with Mouse Anti-E-cadherin Monoclonal Ab (BD Bioscience). The immunoreactive proteins were visualized by enhanced chemiluminescence system. The relative density of the scanned bands was analyzed with Glyko BandScan Analysis Software.

\section{Statistical analyses}

Data were expressed as Mean \pm SE. Comparisons in measurement data were performed by paired $t$ test. Comparisons in enumeration data were performed by Chi-square test or Fisher's Exact Probability test using SPSS 11.0 when appropriate. The difference of $P$ $<0.05$ was considered significant.

\section{RESULTS}

\section{The identification of hairpin siRNA expression plasmid}

A

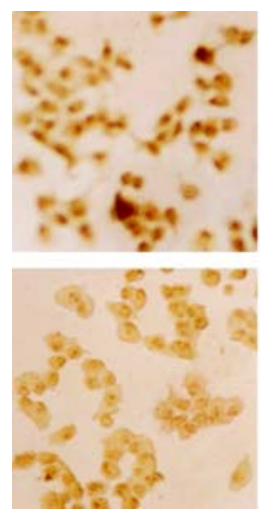

C
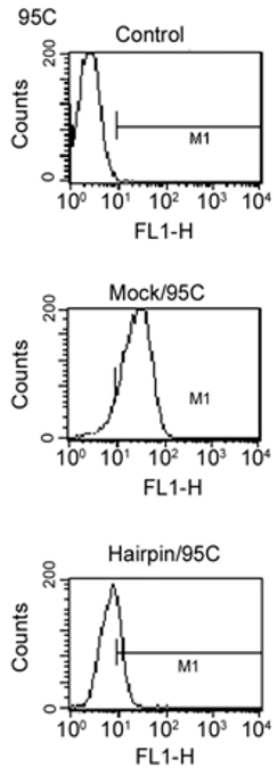
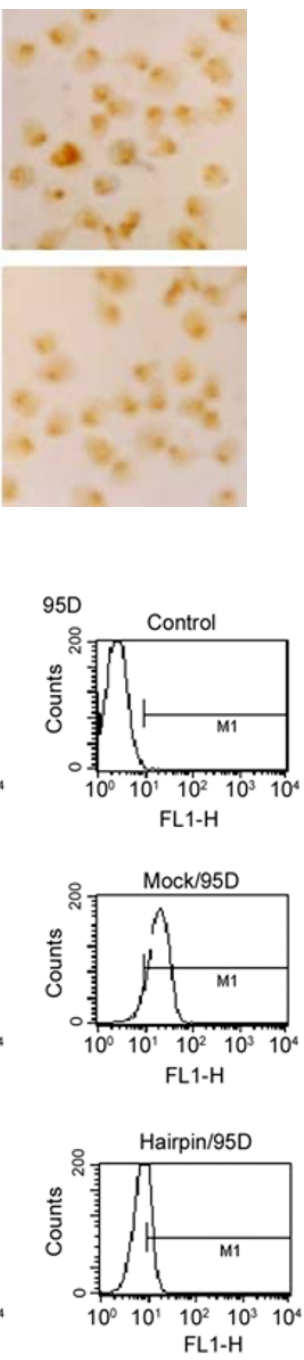

H1 promoter
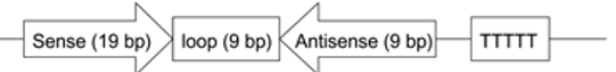

Fig. 1 Construction of hairpin siRNA expression vector.

After the fragment of $\mathrm{H} 1$ promoter amplified by PCR from genome DNA was subcloned into PBluescript SK II $(+)$, catalytic domain of $\alpha-1,6$ FucT targeted hairpin sequence was inserted into +1 position of $\mathrm{H} 1$ promoter (Fig. 1). The RNA is predicted to fold back to form a hairpin dsRNA with a $3^{\prime}$ overhang of 5 Ts as the termination signal for RNA pol III. The construction of RNAi expression vector was confirmed by sequencing.

B
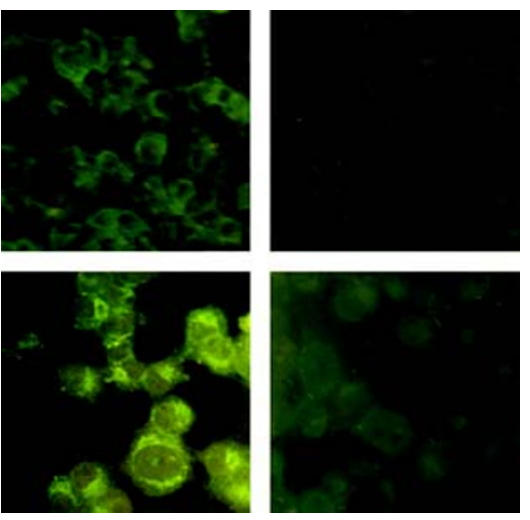

Fig. 2 Apparent decrease of core fucosylation on cellular membrane after $\alpha-1,6$ FucT targeted RNAi. Cells were incubated with Bio-LCA and Avidin-HRP or FITClabeled LCA. Then the result of RNAi had been assayed by (A) immunocytochemical $\mathrm{ABC}$ methods (B) immuno-fluorescence (C) FACS analysis. Results are representative of three independent experiments. 


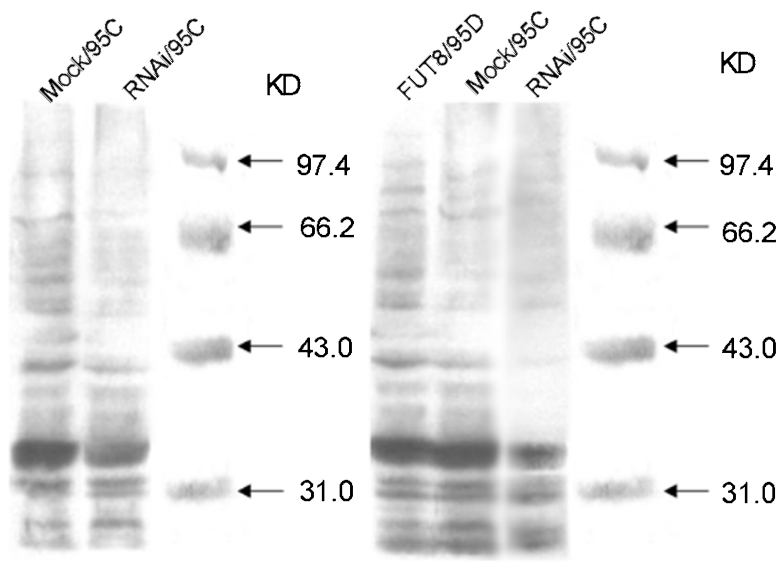

Fig. 3 The effect of $\alpha-1,6$ FucT targeted RNAi and transfecting FUT8 expression vector on core fucosylation detected by lectin blotting using LCA. Results are representative of 3 repeated experiments.

\section{$\alpha-1,6$ FucT targeted RNAi can suppress general core fucosylation of glycoproteins on cell surface}

Since Lens culinaris agglutinin (LCA) can specifically recognize core fucose of N-glycan [15], it was used to detect the levels of core fucosylation which in turn reflect the enzymatic activity of $\alpha-1,6$ FucT. As shown in fig. 2A, $\mathrm{B}$, fluorescent intensity appeared to decline after the transfection of hairpin siRNA expression vector and the fluorescent area of transfected cells was reduced compared with Mocked cells, indicating that core fucosylation on cell surface decreased by $\alpha-1,6$ FucT targeted RNAi. In order to give quantitive support, flow cytometry assay had been performed. Fig. 2C showed the level of core fucosylation. In $95 \mathrm{C}$ cells, it was reduced to $31 \%$ of that of the mocked cells after RNAi, and for 95D cells, the reduction was $64 \%$.

The decrease of core fucosylation induced by RNAi was further demonstrated by Lectin blotting. Fig. 3 showed that the substrates of $90 \mathrm{kD}, 70 \mathrm{kD}, 55 \mathrm{kD}, 50 \mathrm{kD}, 42 \mathrm{kD}$ for $95 \mathrm{C}$ cells and the substrates of $81 \mathrm{kD}, 55 \mathrm{kD}, 50 \mathrm{kD}$, $42 \mathrm{kD}, 38 \mathrm{kD}, 36 \mathrm{kD}$ for $95 \mathrm{D}$ cells were greatly reduced. It could be noted that the reduction of core fucosylation induced by RNAi could be reversed by transfecting with FUT8 expression vector. Core fucosylation on different substrates in FUT8/95D cells had been elevated markedly, especially for substrates of $81 \mathrm{kD}, 75 \mathrm{kD}, 55 \mathrm{kD}, 50 \mathrm{kD}$, $42 \mathrm{kD}$. The above data verified that $\alpha-1,6$ FucT targeted RNAi can successfully suppress general core fucosylation of glycoproteins on cell surface.
A

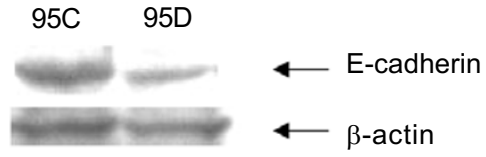

B

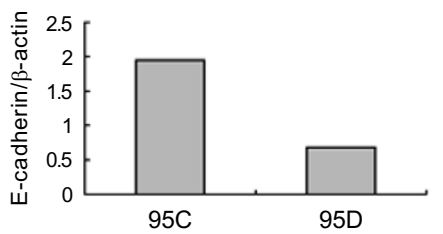

C

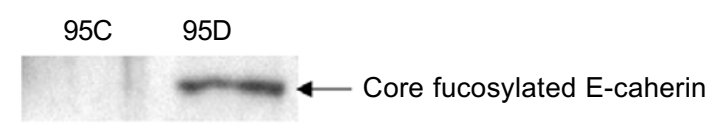

Fig. 4 Differential expression of E-cadherin and core fucosylated Ecadherin in highly and lowly metastatic lung cancer cells. (A) The expression of E-cadherin detected by western blotting. (B) The relative amount of E-cadherin in $95 \mathrm{C}$ and $95 \mathrm{D}$ cells. (C) Detection of core fucosylated E-cadherin by immunoprecipitation and western blotting.

\section{Core fucosylated E-cadherin varied in lowly and highly metastatic lung cancer cells}

The expression of E-cadherin in $95 \mathrm{C}$ cells was higher than that in 95D cells (Fig. 4A, B), which indicated the expression of E-cadherin could be downregulated in highly metastatic cancer cells. By immunoprecipitation and western blotting, no core fucosylated E-cadherin was observed in $95 \mathrm{C}$ cells while a rich supply of core fucosylated E-cadherin was discovered in 95D cells (Fig. 4C). Our findings suggested that core fucosylated Ecadherin could be implicated in cancer metastasis.

\section{a-1,6 FucT targeted RNAi could not affect the total expression of E-cadherin but suppressed core fucosylation of E-cadherin}

95D cells transfected with empty vector served as control. As shown in Fig. 5A, there is no difference in the expression of E-cadherin between Mock/95D and RNAi/ 95D cells. While the expression of core fucosylated Ecadherin in RNAi/95D cells was greatly reduced compared to that of Mock/95D cells (Fig. 5B). This result further confirmed the role of E-cadherin as the substrate of $\alpha-1$, 6 FucT, which was in consistence with Fig. 4.

The expression of core fucosylated E-cadherin was also explored in other cell lines, as illustrated in Fig. 5D, core fucosylated E-cadherin was detected in human cervical carcinoma HeLa, breast carcinoma MCF-7 and ovary caner SKOV-3, while the expression of core fucosylated Ecadherin was absent in lung adenocarcinoma A549, lung 
A

Mock/95D RNAi/95D

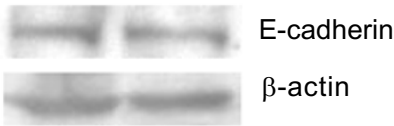

B

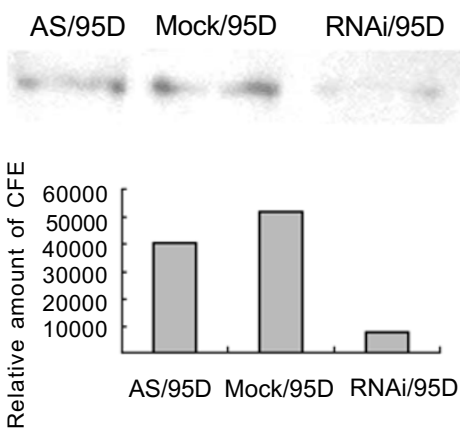

C

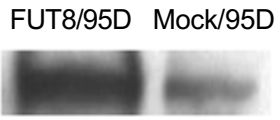

$\mathrm{D}$

HeLa SKOV-3 MCF7 SGC7901 U937 7721

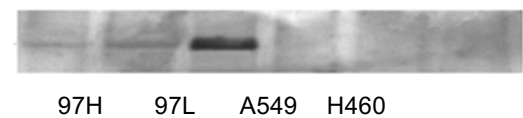

Fig. 5 The expression of E-cadherin and core fucosylated E-cadherin in Mock/95D, RNAi/95D, FUT8/95D cells and other cancer cell lines. (A) The expression of E-cadherin in Mock/95D and RNAi/ 95D cells detected by western blotting. (B) The downregulated expression of core fucosylated E-cadherin caused by RNAi and antisense detected by immunoprecipitation and western blotting. Column graph shows the relative density of bands. AS: antisense. (C) The upregulated expression of core fucosylated E-cadherin caused by transfecting FUT8 expression vector was detected by immunoprecipitation and western blotting. (D) The expression of core fucosylated E-cadherin in different cancer cell lines. Cells were treated as described in "Materials and Methods". The samples were analyzed by western blotting with anti-E-cadherin mAb.

large cell carcinoma H460, gastric carcinoma SGC7901 and histiocytoma U937.

By Fisher's Exact Probability Test with SPSS 11.0, we carried out the statistical analysis of the expression of core fucosylated E-cadherin in the tissue samples and the clinicopathological background of corresponding patients in Tab. 1. Our data showed that the expression of core fucosylated E-cadherin was not correlated with sex $(P=$ $0.152)$, pathological type $(P=0.294)$ or degree of differentiation $(P=0.249)$. Whereas there was significant difference between the expression of core fucosylated E-cadherin and cancer metastasis $(P=0.001)$ as well as prognosis of patients $(P<0.001)$.

\section{$\alpha-1,6$ FucT targeted RNAi promoted cell-cell aggre- gation but did not influence cell adhesion to HUVEC}

Since cell aggregation and attachment to the vascular endothelium are crucial to cancer metastasis, whether and how $\alpha-1,6$ FucT is involved in this process was investigated. Fig. 6 A showed a striking morphological change in $95 \mathrm{D}$ cells caused by $\alpha-1,6$ FucT targeted RNAi. Compared with Mock cells, RNAi/95D cells were inclined to gather together and appeared to aggregate more tightly. However, as illustrated in Fig. 6B, cell adhesion to HUVEC did not change significantly between Mock/95D and RNAi/95D cells. Thus $\alpha-1,6$ FucT could not affect cancer cell adhesion to TNF $\alpha$-activated HUVEC, which was reported to be dependent on sialyl Lewis $^{\mathrm{a}}$ expression [16].

As shown in Fig. 6C, cell-cell aggregation was elevated in RNAi/95D cells compared to Mock/95D cells, while was suppressed in FUT/95D cells, indicating that $\alpha-1,6$ FucT may affect cell-cell aggregation through the modification of core fucosylation on E-cadherin. Given that the differences were calcium-dependent and E-cadherindependent, we came to the conclusion that it is $\alpha-1,6$ FucT targeted RNAi that restored the E-cadherin mediated cell-cell aggregation. Therefore, core fucosylation on Ecadherin should be crucial to the suppression of Ecadherin mediated cell-cell adhesion.

\section{$\alpha-1,6$ FucT targeted RNAi inhibited the prolifera- tion and migration of $95 \mathrm{D}$ cells}

As the substrate of $\alpha-1,6$ FucT, E-cadherin could suppress cancer cell proliferation in a cell adhesion-independent manner. So whether $\alpha-1,6$ FucT is correlated with cell proliferation was investigated. To monitor cell proliferation, MTT assays were conducted over a period of $8 \mathrm{~d}$. We found that $\alpha-1,6$ FucT targeted RNAi could markedly suppress cell growth of 95D in $2 \mathrm{~d}, 4 \mathrm{~d}, 6 \mathrm{~d}$ and $8 \mathrm{~d}$ (Fig. 7), which suggests that $\alpha-1,6$ FucT might exert its function on cell growth via counteracting the function of E-cadherin with core fucosylation.

In order to find out if $\alpha-1,6$ FucT is involved in tumorigenesis and cancer development, $\alpha-1,6$ FucT targeted RNAi was carried out to reveal its metastasis-associated effect. As shown in Fig. 8, by agarose drop method, the moving distance detected in RNAi/95D cells was sig- 
Tab. 1 The expression of core fucosylated E-cadherin in cancer tissue samples from lung cancer patients and the clinicopathological background of patients enrolled.

\begin{tabular}{|c|c|c|c|c|c|}
\hline \multirow[t]{2}{*}{ Lung cancer patients } & & \multicolumn{2}{|c|}{ Expression of CFE } & \multirow{2}{*}{$\begin{array}{l}\text { Positive } \\
\text { rate }\end{array}$} & \multirow{2}{*}{$\begin{array}{l}\text { Fisher's } \\
\text { Exact test }\end{array}$} \\
\hline & & positive & negative & & \\
\hline Condition of metastasis & $\begin{array}{l}\text { With metastasis } \\
\text { Without metastasis }\end{array}$ & $\begin{array}{l}12 \\
0\end{array}$ & $\begin{array}{l}1 \\
5\end{array}$ & $\begin{array}{l}92.3 \% \\
0\end{array}$ & $P<0.01$ \\
\hline \multirow[t]{2}{*}{ Degree of differentiation } & $\begin{array}{l}\text { Poorly } \\
\text { Moderately }\end{array}$ & $\begin{array}{l}5 \\
8\end{array}$ & $\begin{array}{l}0 \\
5\end{array}$ & $\begin{array}{l}100 \% \\
61.5 \%\end{array}$ & $P>0.05$ \\
\hline & Well & 0 & 0 & 0 & \\
\hline \multirow[t]{4}{*}{ Prognosis of patients } & $\begin{array}{l}\mathrm{A} \\
\mathrm{B} 1\end{array}$ & $\begin{array}{l}0 \\
3\end{array}$ & $\begin{array}{l}6 \\
0\end{array}$ & $\begin{array}{l}0 \\
100 \%\end{array}$ & $P<0.01$ \\
\hline & B2 & 2 & 0 & $100 \%$ & \\
\hline & B3 & 6 & 0 & $100 \%$ & \\
\hline & $\mathrm{C}$ & 1 & 0 & $100 \%$ & \\
\hline \multirow[t]{4}{*}{ Pathological type } & $\begin{array}{l}\text { Adenocarcinoma } \\
\text { Squamous carcinoma }\end{array}$ & $\begin{array}{l}8 \\
2\end{array}$ & $\begin{array}{l}2 \\
3\end{array}$ & $\begin{array}{l}80 \% \\
40 \%\end{array}$ & $P>0.05$ \\
\hline & Adenocarcinoma and squamous carcinoma & 0 & 1 & 0 & \\
\hline & Alveolar cell carcinoma & 1 & 0 & $100 \%$ & \\
\hline & Neuroendocrine carcinoma & 1 & 0 & $100 \%$ & \\
\hline \multirow[t]{2}{*}{ Sex } & Male & 5 & 5 & $50 \%$ & $P>0.05$ \\
\hline & Female & 7 & 1 & $87.5 \%$ & \\
\hline
\end{tabular}

CFE: core fucosylated E-cadherin; $\mathrm{P}=$ probability.

A
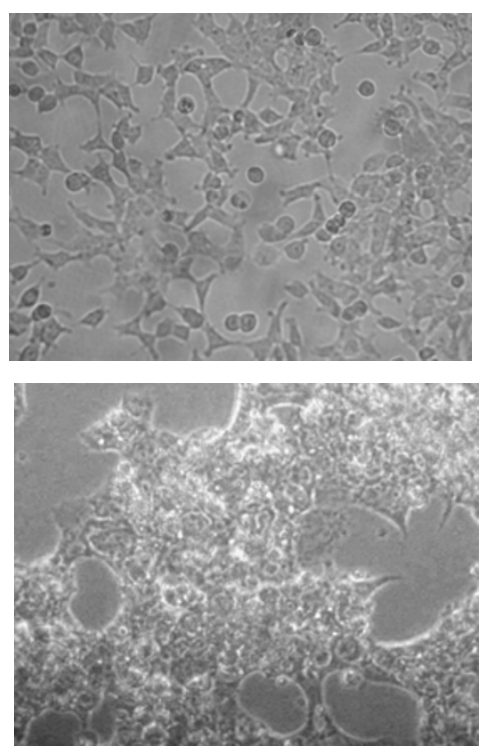

B
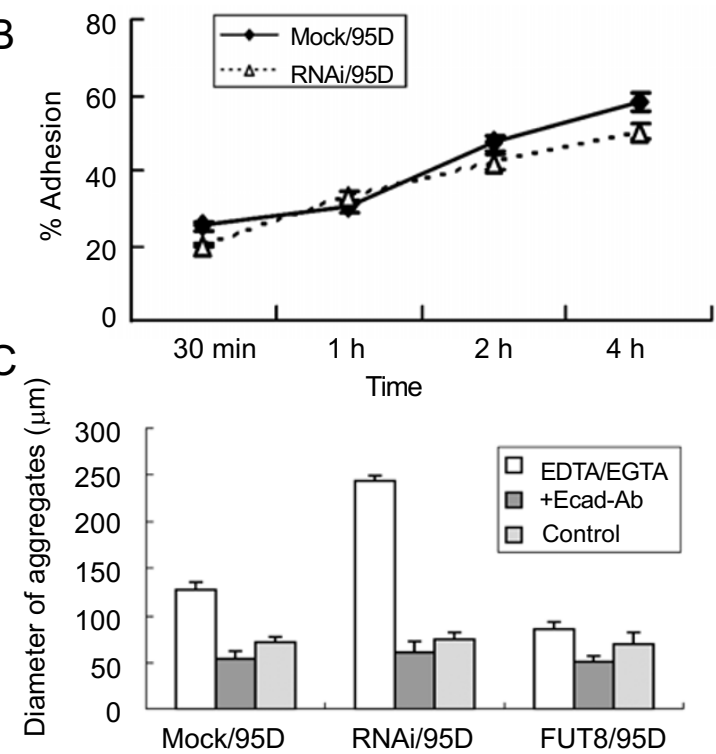

Fig. $6 \alpha-1,6$ FucT targeted RNAi promoted cell-cell aggregation but did not influence cell adhesion to HUVEC. (A) $\alpha-1,6$ FucT targeted RNAi affected morphology of 95D cells. (B) $\alpha-1,6$ FucT targeted RNAi exerted no effects on cell adhesion to HUVEC. The percentage of RNAi/ $95 \mathrm{D}$ cells adherent to human umbilical vein endothelial cells (HUVECs) was compared with Mock/95D cells. HUVECs $\left(4 \times 10^{4} /\right.$ well) were cultured to confluence HUVEC monolayer was then stimulated for $2 \mathrm{~h}$ with $10 \mathrm{ng} / \mathrm{ml} \mathrm{TNF} \alpha$. Mock/95D and RNAi/95D cells were plated at $1 \times 10^{5}$ cellls/well on HUVEC monolayer. After $30 \mathrm{~min}, 1 \mathrm{~h}, 2 \mathrm{~h}, 4 \mathrm{~h}$ of adhesion, unattached cells were vigorously washed away with PBS. Adherent 95D cells were counted under a phase contrast microscope in five random fields in each well. The percentage of adherent cells in total was calculated to show the affinity of cell adhesion to HUVEC. Data was represented as mean \pm SE. (C) Calcium dependent cell-cell aggregation could be promoted by $\alpha-1,6$ FucT targeted RNAi and inhibited by FUT8 overexpression. Cells were allowed to aggregate for 30 $\mathrm{min}$ at $37^{\circ} \mathrm{C}$ with a constant rotation of $70 \mathrm{rpm}$. To examine the calcium dependency, EDTA and EGTA to a final concentration of $5 \mathrm{mM}$ were added. To specify E-cadherin-dependency, $5 \mu \mathrm{g}$ of neutralizing antibody against E-cadherin was added. The extent of cell aggregation was calculated by measurement of the aggregation diameter in each field over a total of five randomly chosen fields. Three independent assays were performed in quadruplicate. Each data represents mean \pm SE. 


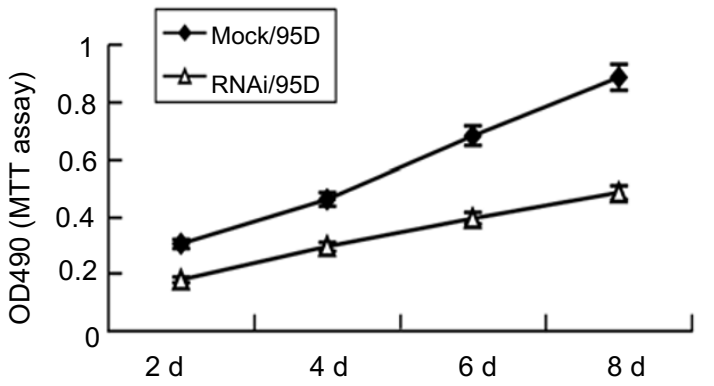

Fig. $7 \alpha-1,6$ FucT targeted RNAi inhibited cell proliferation of 95D detected by MTT assay. Cells were plated at a concentration of $1 \times 10^{4}$ cells per well in four parallel plates. In $2 \mathrm{~d}, 4 \mathrm{~d}, 6 \mathrm{~d}$ and $8 \mathrm{~d}$, one plate was used for cell proliferation assay. In the MTT assay, cells were placed in growth medium with $1 \mathrm{mg} / \mathrm{ml}$ of MTT. Cells were incubated at $37^{\circ} \mathrm{C}, 5 \% \mathrm{CO}_{2}$ for $4 \mathrm{~h}$. The medium was aspirated and the formazan crystals were dissolved in $200 \mu \mathrm{l}$ DMSO. The absorbance at $490 \mathrm{~nm}$ was determined by an $\mathrm{EL}_{\mathrm{X}} 800$ Microplate Reader. All proliferation assays were carried out in quadruplicate wells in 96well microtiter plates.

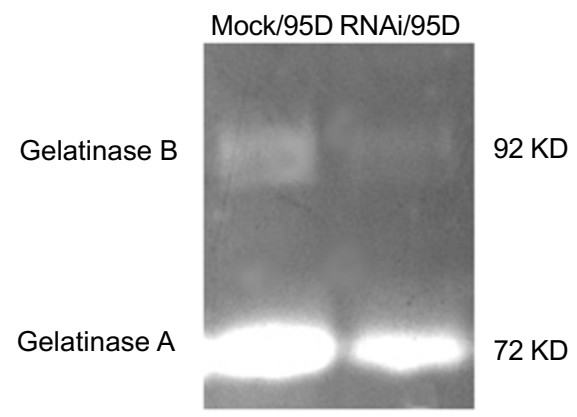

Fig. 9 RNAi reduced gelatinase activity detected by zymography of CCM derived from Mock/95D and RNAi/95D cells. $30 \mu \mathrm{lCCM}$ was loaded on a $10 \%$ SDS-PAGE as described under Materials and Methods. This illustration is representative of three independent experiments.

nificantly reduced when compared with the distance of Mock $/ 95 \mathrm{D}$ cells (reduced by $29.0 \%$ at $24 \mathrm{~h}$ and $23.2 \%$ at $48 \mathrm{~h}, P<0.05$ ). The result demonstrated that $\alpha-1,6$ FucT was involved in the motility of cancer cells by promoting the metastatic potential, which was in contrary to the function of E-cadherin.

\section{Gelatinase activity decreased after $\alpha-1,6$ FucT targeted RNAi}

Zymograhy had been performed using CCMs from Mock/95D and RNAi/95D cells of the same concentration. Cells were cultured for $24 \mathrm{~h}$ with serum deprivation in order to avoid the inhibition by $\alpha 2$-macroglobulin. The same volumes $(30 \mu \mathrm{l})$ were loaded with $0.5 \%$ gelatin. As

\section{A}

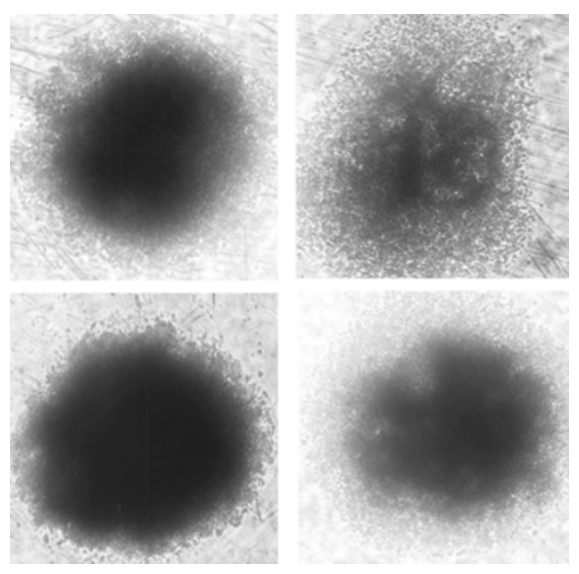

B

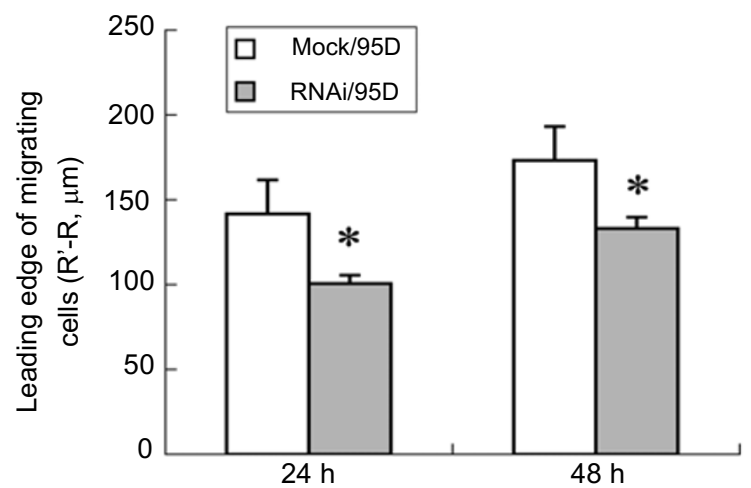

Fig. 8 Random migration of Mock/95D cells and RNAi/95D cells assayed by agarose drop explants. (A) Random migration of Mock/ 95D and RNAi/95D cells at $24 \mathrm{~h}$ and $48 \mathrm{~h}$. (B) Cell migration was measured by the distance of leading edge of migrating cells from the edge of agarose droplet (R'-R) using inverted microscope fitted with a ruler in eyepiece. Data were represented as Mean $\pm \mathrm{SE}(* P<0.05)$.

illustrated in Fig. 9, two types of gelatinase/MMP activities were observed in CCMs, one major band corresponding to MMP-2 $(72 \mathrm{kD})$ and a minor band at $92 \mathrm{kD}$ corresponding to MMP-9. Both the relative activity of MMP-2 and MMP-9 decreased in RNAi/95D cells. Since E-cadherin could suppress MMP activity [17], $\alpha-1,6$ FucT might restore MMP activity by adversely regulating E-cadherin mediated inhibition.

The addition of core fucose to E-cadherin could destroy three-dimensional conformation of $\mathrm{N}$-glycan on E-cadherin

Since the CAD1 domain of E-cadherin is essential for cell-cell contact, we constructed the molecular model of 


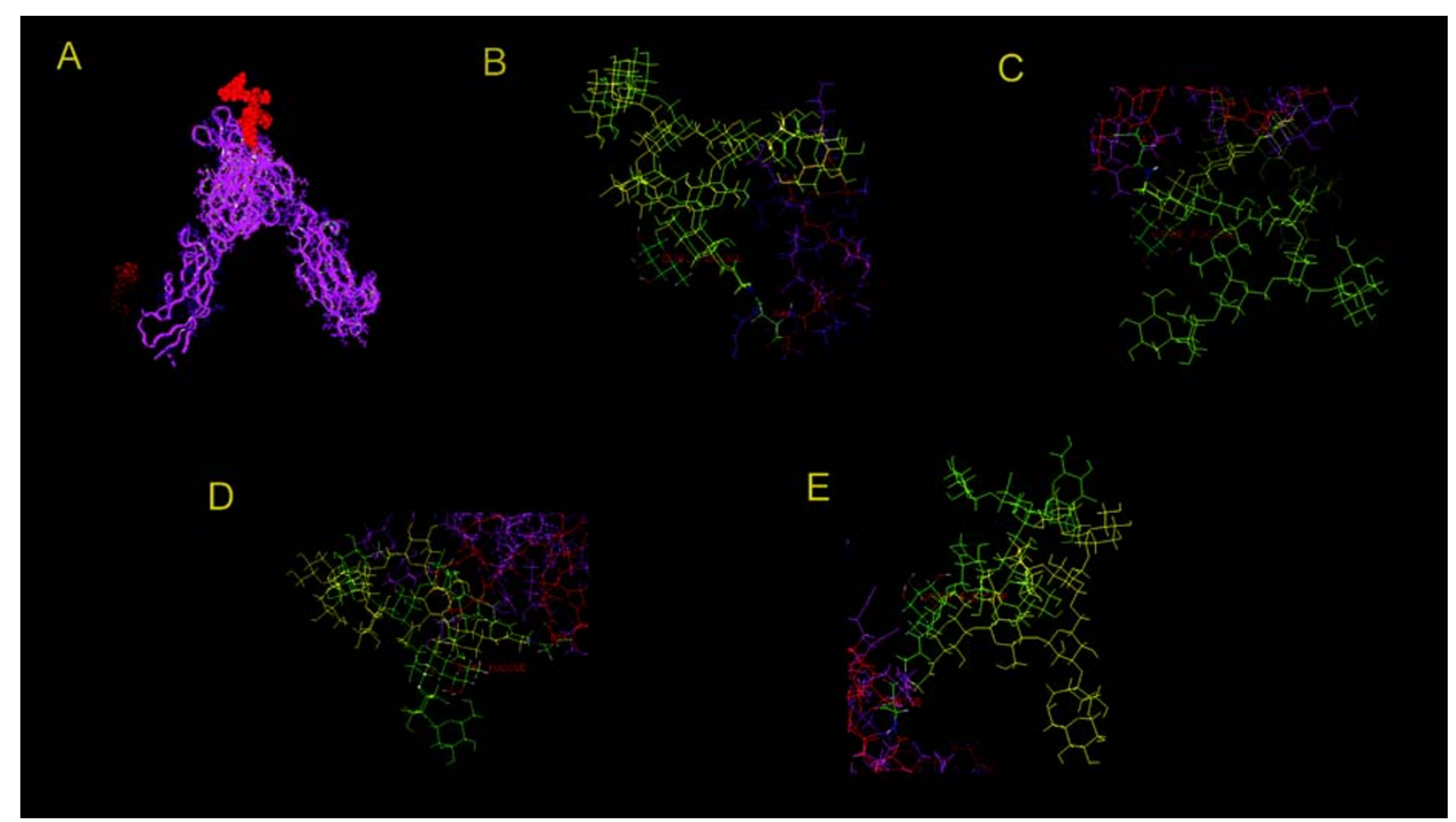

Fig. 10 Computer modeling of core fucosylation on E-cadherin. (A) Computer modeling of E-cadherin (cis dimers of domain CAD1) containing N-linked glycans without core fucosylation. Ball and stick model: red balls show N-glycans; purple chains show backbone of Ecadherin (cis dimers of domain CAD1). (B-E) The effect of core fucosylation modification on the conformation of N-glycan on E-cadherin (the glycosylation site of residue Asn238 and Asn320 on the dimer composed of A and B chain). Green chains show N-glycan without core fucosylation; yellow chains show core fucosylated $\mathrm{N}$-glycan; red and purple chains show amino acid residues.

cis dimerisation of glycosylated domain CAD1 (A chain, B chain) by computer modeling according to crystal structure of E-cadherin and glycan structure of E-cadherin [7] (Fig. 10A). By analyzing steric effect and forcefields, we ascertained that potential glycosylation sites (Asn-X-Ser/ Thr) on domain CAD1 of E-cadherin are Asn238 and Asn320. The molecular modeling of core fucosylation reaction on E-cadherin was also performed. Distinguishing from the conformation of $\mathrm{N}$-glycan on E-cadherin without core fucosylation (green chains) and with core fucosylation (yellow chains), our data (Fig. 10B) showed that the presence of core fucose on Asn320 (A chain), Asn238 and Asn 320 (B chain) could apparently alter the conformation of $\mathrm{N}$-glycan on E-cadherin while the conformation of $\mathrm{N}$-glycan on E-cadherin is intact by the addition of core fucose on Asn238 (A chain). The result demonstrated that core fucosylation on E-cadherin could impair Ecadherin mediated cell adhesion by conformational changes in $\mathrm{N}$-glycan because $\mathrm{N}$-glycan plays an important role in the process $[10,18]$. Moreover, symmetric dimers of CAD1 are essentially required for dimerization and cellcell adhesion [5]. Therefore, the asymmetric conformation of N-glycans on core fucosylated E-cadherin could abolish the function of E-cadherin due to the intact conformation on Asn238 (A chain) contrasted with altered conformations on the other three glycosylation sites.

\section{DISCUSSION}

It has been well reported that the modification of Ecadherin by glycosyltransferase is of great importance to cancer metastasis [18]. By studying the congenetic lung cancer cell lines with different invasive and metastatic potential [19], we found that core fucosylated E-cadherin was selectively expressed in highly metastatic lung cancer cells while absent in lowly metastatic lung cancer cells. We confirmed that E-cadherin is the substrate of $\alpha-1,6$ FucT and provided evidence to suggest that its expression is closely correlated with cancer metastasis.

To elucidate the role of $\alpha-1,6$ FucT in malignant behavior of cancer, we carried out $\alpha-1,6$ FucT targeted RNAi, for which the sequence of 789-808 bp encoding catalytic domain of $\alpha-1,6$ FucT was selected as targeted sequence. By BLAST we ascertained that no other homologous genes existed in lung cancer cells. The effect of RNAi had been assayed by immunocytochemical ABC method, immunofluorescence staining, flow cytometry analysis and lectin blotting. 
Superior to antisense in targeted gene silencing, $\alpha-1,6$ FucT targeted RNAi suppressed core fucosylation of Ecadherin significantly, which also ascertained that Ecadherin could be the substrate of $\alpha-1,6$ FucT in accordance with the results of immunoprecipitation and western blotting in 95D cells. Since the expression of core fucosylated E-cadherin was correlated positively with the cancer metastasis, we assumed that the function of E-cadherin might be negatively regulated by $\alpha-1,6$ FucT. As a result of $\alpha-1,6$ FucT targeted RNAi, there is a reduction in the expression of core fucosylated E-cadherin while the expression of E-cadherin was intact. At the same time, E-cadherin mediated calcium dependent cell-cell aggregation had been strengthened, which strongly suggested the function of E-cadherin has been restored due to the suppression of $\alpha-1,6$ FucT. We came to the conclusion that core fucosylation on E-cadherin plays a negative role on its function, which was further supported by inhibition of cell-cell aggregation induced by elevated expression of core fucosylation on E-cadherin when $\alpha-1,6$ FucT was overexpressed.

Both MMP-2 and MMP-9 are two proteases most frequently expressed in cancer metastasis and angiogenesis as well as for cell migration or invasiveness [13]. By zymography, our data showed that the activity of MMP-2 and MMP-9 in RNAi/95D cells decreased compared to Mock/95D cells. As E-cadherin could mediate MMP downregulation in highly invasive bronchial tumor cells [16], core fucosylation on E-cadherin might restore MMP activity via counteracting the function of E-cadherin.

According to crystal data of E-cadherin, we carried out prediction for structure and function of core fucosylated E-cadherin (cis dimers of domain CAD1). Possible threedimensional structure of core fucosylated E-cadherin had been achieved and demonstrated. The presence of core fucose could dramatically destroy normal three-dimentional conformation and flexibility of N-glycan on E-cadherin so as to impair its function. This explained why $\alpha-1,6$ FucT targeted RNAi could promote cell aggregation and downregulate MMP activity which seems to restore the function of E-cadherin without changing its expression. Furthermore, the only addition of core fucose on Asn238 (A chain) of cis-dimers does not affect the conformation and flexibility of $\mathrm{N}$-glycan on E-cadherin, suggesting much asymmetry will arise in crystal structure at $2.0 \AA$ resolution of the two N-terminal extracellular domains of $E$ cadherin which should be a two-fold symmetric dimer [5]. We assume the asymmetry will be interfere with the clustering of cis dimers and the formation of lateral bonds, which could greatly supress E-cadherin mediated cell adhesion. This further suggests the possible molecular mechanism by which core fucosylation inhibits E-cadherin function.

The expression of core fucosylated E-cadherin in other cancer cell lines and lung cancer tissue samples was explored to reveal the biological importance of its presence. The results demonstrated that in different cancer cell lines (breast, ovary, stomach, cervical, lung and liver) there are, different the expression levels of CFE are different. It is fairly exciting that core fucosylated E-cadherin is present in highly metastatic cancer cells (95D, MHCC97-H) while there is entirely loss of its expression in lowly metastatic cancer cells (95C, SMMC-7721, MHCC97-L), which suggests that there might be some definite correlation between core fucosylated E-cadherin expression and cancer metastasis.

Lung cancer, the common cause of death in China, is frequently highly invasive or metastatic at the time of initial diagnosis [20]. To elucidate the clinical meaning of core fucosylated E-cadherin, we investigated the relationship between its expression in tissue samples of lung cancer and the clinicopathological background of corresponding patients. Our data showed that the expression of core fucosylated E-cadherin was closely related to prognosis of patients and cancer metastasis. Moreover, statistical analysis revealed no correlation between its expression and pathological type, sex or differentiation degree, thus providing the specificity of core fucosylated E-cadherin as prognostic factor. In addition, slight expression of core fucosylated E-cadherin could be detected in margin tissues while absent in inflammatory pseudotumor, indicating that the sensitivity of core fucosylated E-cadherin is specific to highly metastatic cancer. However, although the decreased expression of E-cadherin showed parallel with lymph node metastasis in lung cancer, it did not correlate with the prognosis of lung cancer patients [20].

Above all, we assume that core fucosylated E-cadherin serves as a promising marker for cancer metastasis and prognosis of lung cancer patients, so our study shed light on clinical prognostic evaluation of lung cancer.

\section{ACKNOWLEDGEMENTS}

This work was supported by the National Nature Science Foundation of China (No. 30070183) and Key Subject Foundation of Shanghai Municipal Education Committee (No. B9808010).

Received, Feb 4, 2004

Revised, Jun 6, 2004

Accepted, Jun 18, 2004

\section{REFERENCES}

1 Geng $\mathrm{F}, \mathrm{Wu}$ XZ. The advances in the research of $\alpha-1,6$ Fucosyltransferase. Chemistry of life Sinica 2003; 2:118-20 
2 Christofori G, Semb H. The role of the cell-adhesion molecule Ecadherin as a tumor- suppressor gene. Trends Biochem Sci 1999; 24:73-6

3 Beavon IR. The E-cadherin-catenin complex in tumor metastasis: structure, function and regulation. Eur J Cancer 2000; 36: 1607-20

4 Wijnhoven BP, Dinjens WN, Pignatelli M. E-cadherin-catenin cell-cell adhesion complex and human cancer. Br J Surg 2000; 87: 992-1005

5 Nagar B, Overduin M, Ikura M, Rini JM. Structural basis of calcium-induced E-cadherin rigidification and dimerization. Nature 1996; 380:360-4

6 Guo HB, Lee I, Kamar M, Pierce M. N-acetylglucosaminyltransferase $\mathrm{V}$ expression levels regulate cadherin-associated homotypic cell-cell adhesion and intracellular signaling pathway. J Biol Chem 2003; 278:52412-24

7 Przybylo M, Hoja-Lukowicz D, Litynska A, Laidler P. Different glycosylation of cadherins from human bladder non-malignant and cancer cell lines. Cancer Cell Int 2002; 2:6

8 Hannon GJ. RNA interference. Nature 2002; 418:244-51

9 Paddison PJ, Caudy AA, Hannon GJ. Stable suppression of gene expression by RNAi in mammalian cells. Proc Natl Acad Sci USA 2002; 99:1443-8

$10 \mathrm{Yu}$ JY, DeRuiter SL, Turner DL. RNA interference by expression of short interfering RNAs and hairpin RNAs in mammalian cells. Proc Natl Acad Sci U S AU.S.A 2002; 99:6047-52

11 Xu Z, Shen MX, Ma DZ, Wang LY, Zha XL. TGF- $\beta 1$-promoted epithelial-to-mesenchymal transformation and cell adhesion contribute to TGF- $\beta 1$-enhanced cell migration in SMMC-7721 cells. Cell Res 2003; 13:343-50
12 Menke A, Philippi C, Vogelmann R, et al. Down-regulation of Ecadherin gene expression by collagen type I and type III in pancreatic cancer cell lines. Cancer Res 2001; 61:3508-17

13 Oliver L, Tremblais K, Guriec N, et al. Influence of bcl-2-related proteins on matrix metalloproteinase expression in a rat glimoma cell line. Biochem Biophys Res Commun 2000; 273:411-6

14 Petrescu AJ, Petrescu SM, Dwek RA, Wormald MR. A statistical analysis of $\mathrm{N}$ - and O-glycan linkage conformations from crystallographic data. Glycobiology 1999; 9:343-52

15 Miyoshi E, Noda K, Yamaguchi Y, et al. The $\alpha 1,6$-fucosyltransferase gene and its biological significance. Biochim Biophys Acta 1999; 1473:9-20

16 Flugy AM, D'Amato M, Russo D, et al. E-selectin modulates the malignant properties of T84 colon carcinoma cells. Biochem Biophys Res Commun 2002; 293:1099-106

17 Nawrocki-Raby B, Gilles C, Polette M, et al. E-Cadherin mediates MMP down-regulation in highly invasive bronchial tumor cells. Am J Pathol 2003; 163:653-61

18 Kitada T, Miyoshi E, Noda K, et al. The addition of bisecting Nacetylglucosamine residues to E-cadherin down-regulates the tyrosine phosphorylation of $\beta$-catenin. J Biol Chem 2001; 276: 475-80

19 Lu YL, Huang JX, Li XH, et al. Spontaneous metastasis of clonal cell subpopulations of human lung giant cell carcinoma after subcutaneous inoculation in nude mice. Zhonghua Zhong Liu Za Zhi 1989; 11:1-7 (In Chinese)

20 Kase S, Sugio K, Yamazaki K, et al. Expression of E-cadherin and $\beta$-Catenin in human non-small cell lung cancer and the clinical significance. Clin Cancer Res 2000; 6:4789-96 